\title{
Actor-centred emergency response systems: a framework for needs analysis and information systems development
}

Kayvan Yousefi Mojir and Sofie Pilemalm

Journal Article

Tweet

N.B.: When citing this work, cite the original article.

Original Publication:

Kayvan Yousefi Mojir and Sofie Pilemalm, Actor-centred emergency response systems: a framework for needs analysis and information systems development, International Journal of Emergency Management, 2016. 12(4), pp.403-434.

http://dx.doi.org/10.1504/IJEM.2016.10000709

Copyright: Inderscience

http://www.inderscience.com/

Postprint available at: Linköping University Electronic Press

http://urn.kb.se/resolve?urn=urn:nbn:se:liu:diva-132364

I..0 


\title{
Actor-Centred Emergency Response Systems:
}

\author{
A framework for needs analysis and information systems development
}

\author{
Kayvan Yousefi Mojir* \\ Department of Management and Engineering, Linköping University \\ 58183 Linköping, Sweden \\ kayvan.y.mojir@liu.se \\ Sofie Pilemalm \\ Department of Management and Engineering, Linköping University \\ 58183 Linköping, Sweden \\ sofie.pilemalm@liu.se \\ *Corresponding author
}

\section{Biographical notes:}

Kayvan Yousefi Mojir is a Ph.D. student in Information Systems Development at the Department of Management and Engineering, Information Systems division at Linköping University in Sweden. He started his Ph.D. studies in 2012. He performs research in the field of information systems and emergency response systems. His current subject is about involving new actors within emergency response systems and analysing new forms of collaboration between actors in these kinds of systems. He has several scientific publications in this area and has presented his results, e.g. at the International Conference for Information Systems in Crisis Management (ISCRAM).

Dr Sofie Pilemalm is Professor in Informatics and the Director of Centre for Advanced Research of Emergency Response (CARER), residing at Linköping University, Sweden. She received her Ph.D. in 2002 and has since worked as Researcher and Consultant for the Swedish Defence Research Agency before returning to the university in 2011. She is currently working with establishing a new research environment in terms of new actors, new collaboration forms, new structures and new methods and ICT support in emergency management and the incident site of the future. Sofie Pilemalm has many years of experience in user-centred systems development and has led several systems development projects and design groups in such areas as non-profit organizations, the Swedish Defence, crisis management and response systems. She is an active researcher in the security arena both at national and international level and has a great number of publications and review assignments in related scientific journals and conferences. She has hosted tracks on emergency management, e.g. at the International Conference for Information Systems in Crisis Management (ISCRAM).

\begin{abstract}
A new trend in Emergency Response Systems (ERSs) is to create new forms of collaboration, for example, by involving new resources in response operations. It is aimed to enable more effective and faster operations in situations in which existing professional resources are insufficient. However, the fact that the new resources come from different organisational contexts and social sectors creates new challenges and directly affects information systems development for the resources/actors involved. The challenges should be considered in the early stage of analysis when developing such systems. This study contributes by developing and presenting a novel framework to analyse the new forms of collaboration, with a specific focus on information systems development. The framework includes fifteen dimensions, such as, e.g., task, responsibility, incident type, and legal problems. Socio-technical system theory and participatory design approaches are applied to make the framework usable in the information systems field. The framework can also address problems such as the lack of
\end{abstract}


formalisation and difficulties in identifying relevant stakeholders in participatory design. The investigation was performed as a case study based on Swedish data, circumstances and experiences. However, a comparison with international research showed that the Swedish ERS can be seen as an instantiation of ERSs throughout the world that also reflects global cross-sector collaboration trends in the public sector and shares many challenges. The framework can, therefore, be adapted to ERSs in other countries or even to other parts of the public sector that are undergoing similar changes.

Keywords: Emergency response systems, new actors, new forms of collaboration, cross-sector collaboration, information systems, socio-technical systems, participatory design, needs analysis

\section{INTRODUCTION}

In the public sector, various challenges—such as resource shortages and financial cutbacks resulting from the global financial crisis - have prompted organisations to seek help from other organisations and societal sectors. The aim is to create redundancy in societal systems (Alter \& Hage, 1993; Fleishman, 2009; Gazley, 2008; Levine \& White, 1961; Thomson \& Perry, 2006). In the recent decade, new forms of collaboration — such as cross-sector collaboration, inter-organisational collaboration and the involvement of volunteers-have been discussed as potential solutions to various challenges such as climate change, natural resource management, natural disasters, and emergency management (e.g. Agranoff, 2007; Agranoff \& McGuire, 2010; Bryson et al., 2006; Goldsmith \& Eggers, 2004; O’Leary \& Bingham, 2009)

Emergency Response Systems (ERSs) aim to save lives and minimise damage to the environment in the case of emergency situations. As a part of the public sector, they face challenges such as cutbacks in resources and long distances between emergency management organisations and the population in sparsely populated areas. Such challenges cause delay in response operations and lead to more injuries and environmental damage, and thus require new strategies and means to organise the response system. Involving complementary societal resources (in this study they are called new actors ) and creating new forms of collaboration and redundancy in ERSs may allow for faster and more effective responses, thereby saving more lives and mitigating environmental damage (Lee \& Winters, 2012; Pilemalm et al., 2013; Sund, 2006). Such strategies may include: 1) involvement of volunteer groups, 2) permanent co-location of response organisations and supportive actors in terms of authorities and non-profit organisations, and 3) cooperative use of resources in which different organisations and societal sectors share resources, equipment and alarm centres (e.g. Gunnarsson \& Svavarsdóttir, 2007; Larson et al., 2006; Stenberg et al., 2010; Venema et al., 2010; Yousefi Mojir \& Pilemalm, 2014) . However, research on new collaborations and organisation forms of emergency response is new and unexplored (e.g. Pilemalm et al., 2013).

The availability of information systems - in this paper defined as a package of information technology equipment, people, tasks, devices, and policies and their interaction (Orlikowski \& Iacono, 2001)—is central in ERSs and to cross-sector and inter-organisational collaboration in general: for example, for sharing information, making decisions, and facilitating communication (Walle \& Turoff, 2008). New ways of organising ERSs also create corresponding new user needs for information systems, which should be carefully examined so that they can be met. There are still many unanswered questions about new forms of collaboration and related challenges, as well as their impact on information systems development. Unsolved issues include, for example, defining the proper responsibilities of actors in the new settings, establishing information needs, and addressing legal issues in information sharing (Grudinschi et al., 2013; Pilemalm et al., 2013). It may even be that existing methods, routines, policies, and laws must be challenged. In addition, the perceived user group is heterogeneous. For example, organised actors (such as the Red Cross) likely have different needs than unorganised actors, e.g. individual volunteers. Previous research has shown that it is difficult to design information systems without considering the specific characteristics of ERSs and the actors taking part in response operations (Schraagen \& Ven, 2011; Turoff et al., 2004; Yousefi Mojir \& Pilemalm, 2013). It is therefore crucial to rigorously analyse ERSs early on in related information systems development so as to minimise the risk of project failure. This 
study contributes by developing and presenting a framework to use in information systems development in the context of ERSs, with a specific focus on new forms of collaboration.

\section{STUDY AIM AND OBJECTIVES}

The aim of this paper is thus to present a conceptual framework for the analysis of ERSs and particularly for the analysis of new forms of collaboration. The specific research objectives include:

- To present a framework in which the important aspects of new forms of collaboration are categorised and highlighted;

- To describe the way the framework can be used for information systems development in ERSs.

The framework can be used at a general level for the analyses of new forms of collaboration in ERSs. It provides a formal and a structured way of performing analyses and is intended to be used as a support for both researchers and practitioners. Socio-technical system theory and participatory approaches were added to enrich the framework and enhance its applicability in the information system field specifically, by incorporating actors and their needs in the development process. Therefore, the framework is specifically targeted toward enhancing information systems development in the context of ERSs and intended to facilitate the development of broad and organisationally feasible IT solutions based on actors' needs. In a wider sense, the framework could contribute to formalisation of participatory systems development in general, which is subsequently discussed in the paper.

The improvement of new forms of collaboration between actors is not the main objective of the framework. However, it is apparent that by gaining a deeper understanding of this phenomenon and by developing appropriate ISs for involved actors, it is possible to achieve a better collaboration. Entering a new domain when performing IS development often involves creating frameworks to structure the domain and there exist other frameworks and models with similar objectives. However, they are either general frameworks aimed at analysing collaboration and are not bound to ERSs and ISs (e.g. Bryson et al., 2006), they are at an abstract level and not practically connected to the IS field (e.g. Rasmussen \& Svedung, 1997), they are specifically for IS development processes but do not involve specific characteristics of ERSs (e.g. Baxter \& Sommerville, 2011) or they are developed for specific purposes such as understanding decision making (Ki Kim \& Sharman, 2006). Therefore, there was a perceived need to develop a new framework which is particularly constructed for new forms of collaboration in ERSs and which can be used practically in analysis of collaboration and the development of related ISs.

\subsection{Definitions}

As to definitions, the term 'new forms of collaboration' is used to highlight recent trends of cross-sector and intra-organisational collaboration in ERSs involving actors many of whom did not previously play an important part in emergency response but who are increasingly integrated in the ERSs. The term 'actor' is used to refer to the organisations, communities, groups and individuals that are involved directly in response operations, are connected to ERSs or have the potential to be involved in emergency response. Actors may be indirect users or direct users of ISs. The latter are also called end-users in the paper.

\section{BACKGROUND}

This section provides an overview of socio-technical systems theory and participatory design and their application in the field of ERSs. It also explains new strategies and new forms of collaboration worldwide and in the Swedish ERS. 


\subsection{Socio-technical systems}

Socio-technical system thinking was originally initiated by Emery and Trist in order to describe a system with complex interactions. They argued that in order to understand and gain a better picture of a system, the social dimension of a system including environmental, contextual and human aspects should be taken into account. As a result, they used the term 'socio-technical system' to present the need to analyse jointly the social and technical aspects in systems (Emery \& Trist, 1960). Although the underlying philosophy of socio-technical system thinking has not changed remarkably, its applications and principles have developed and extended during the last 60 years. For example, it has been applied practically to design of new technologies and specifically IT systems (e.g. Baxter \& Sommerville, 2011). Organisational design has widely accepted socio-technical system thinking in redesigning jobs and work processes both for more effective systems and better work conditions for employees (e.g. Grant et al., 2011). As related to emergency management, socio-technical system thinking has been applied to risk management (Rasmussen \& Svedung, 1997), accident analysis and causation (Walker et al., 2012), and in safety engineering for designing safer software (Leveson, 2012) . Communication and sensemaking skills have been highlighted as important human factors in emergency response operations and the design of associated information systems (Schraagen \& Ven, 2011). Relationships between culture, technology and structure have also been shown to be significant factors when analysing high-risk organisations from a socio-technical point of view (Nævestad, 2009).

There are some key characteristics for a system to be considered as a socio-technical system. First the system should have interdependent parts and pursue explicit goals. System should have internal environment including social and technical subsystems. System performance depends on the joint-optimisation of technical and social subsystems and focusing on only one may lead to system failure and lack of performance (Baxter \& Sommerville, 2011; Mumford, 2006). It has also been argued that socio-technical-based system analysis is especially appropriate for systems characterised by uncertainty and complexity that require timely, relevant and accurate information and the ability to adapt to change (Coakes, 2002). Since ERSs clearly display the key characteristics described above, and also are systems in line by the characterisation provided by Coakes, a framework based on socio-technical system theory seems suitable. Moreover, socio-technical system theory provides a clear reasoning for how to develop a framework from a theoretical perspective and how to insert it into the context of participatory system development.

\subsection{Systems development: Participatory Design}

It has been claimed that most failures in information systems development projects stem from poor analysis of user needs and incomplete elicitation of system requirements by system developers (Boehm \& Papaccio, 1988; Young, 2002). It is generally difficult to gain a comprehensive user-level understanding and this is for several reasons as for example: (Avison \& Fitzgerald, 2006; Christel \& Kang, 1992; Sommerville, 2004).

- System developers have a poor knowledge and experience about the problem domain and user context. -Users do not have enough knowledge about technological capabilities and limitations.

-Users may know their concerns and problems, but they do not usually know how to express them as needs.

-Users and system developers have different views on the new system and cannot agree on the requirements.

From a socio-technical system theory point of view, the interaction between users and technology are not limited neither to technical factors nor social factors but to both. However the theory itself does not focus on the explicit role of users and relevant stakeholders in technology design. There are other more practical approaches that explicitly highlight just this role: e.g. user-centred design, cooperative design, and participatory design (Ehn \& Kyng, 1987; Greenbaum \& Kyng, 1991; Karat, 1996; Norman \& Draper, 1986; Schuler \& Namioka, 1993). For instance, participatory design stemmed from socio-technical system theory and relies on the direct involvement of stakeholders throughout the technological development process in order to ensure that the final product meets their needs (Ehn, 1993; Ehn \& Kyng, 1987; Mumford, 2000). 
Despite the benefits of user-participation approaches—for example, in grasping users' needs for information systems, better acceptability of systems by end-users, and improved end-user satisfaction — there are also a number of problems associated with them. Examples include the lack of formalisation in user involvement processes, problems in user identification where users are heterogeneous, and dealing with complex contexts in which there are different organisations with different needs and perspectives (Cavaye, 1995; Karlsson et al., 2012; Oostveen \& van den Besselaar, 2004). These problems are intensified when developing information systems to accommodate new forms of collaboration, in which actors' tasks, needs and responsibilities are not well defined and where user groups are often markedly heterogeneous and may come from different societal sectors. Therefore, user-participatory design was found to be appropriate for this study because of its direct emphasis on the participation of relevant stakeholders in the analysis and development processes. At the same time it will be discussed how the framework has the potential to formalise and facilitate the application of participatory design in relevant projects.

\subsection{New strategies and forms of collaboration in emergency response}

ERSs are complex systems that encompass numerous organisations, individuals, systems, techniques, and methods, often with limited or even scarce resources, with the goal of saving lives and minimising environmental damage in the case of emergency situations (Haddow et al., 2013). An ERS, as a specific context, usually deals with limited, delayed, and sensitive information, time pressures, exception-filled routines and a highly collaborative working environment with flexible teams of first responders. A challenge in contemporary society is to continue improving ERSs by reducing the response time and increasing the response quality, balancing scarce resources with rising public expectations (Wankhade \& Murphy, 2012 ). ERSs are part of the public sector, which in turn is marked by a general trend to seek help from others and to establish cross-sectoral collaborations (Agranoff, 2007; Kettl, 2005; Vigoda, 2003). The emergence of new forms of collaboration that use volunteers, off-duty personnel and bystanders in ERSs are considered an important shift in emergency management (e.g. Gunnarsson \& Svavarsdóttir, 2007; Larson et al., 2006; Stenberg et al., 2010; Venema et al., 2010; Waugh \& Streib, 2006). Specifically in sparsely populated areas with long distances between response organisations and the population, informal structures, social networks, volunteer help, and non-profit groups play significant roles (Lee \& Winters, 2012; Pilemalm et al., 2013). A central part of an ERS is having information systems that support decision making, facilitate communication, enable information sharing, provide geographical information, situational awareness, train actors, etc. (Chen et al., 2007; Walle \& Turoff, 2006; Woltjer et al., 2006). Information systems cannot be ignored when developing and studying new forms of collaboration in ERSs, and therefore new challenges should be identified and considered when developing them.

While the benefits of new forms of collaborations in ERSs have begun to receive recognition in both research and practice, there are associated gaps, difficulties and challenges, such as the different types of new actors, their role in emergencies, their responsibilities, tasks, and required competences ( Pilemalm et al., 2013). Yousefi Mojir and Pilemalm (2013) address this by looking at different types and dimensions of new actors. It has been claimed that the research on new actors in ERSs usually adopts a limited view that is either technical or medical, without any organisational and social considerations (Hallstrom, et al., 2004; Stenberg et al., 2010; Weisfeldt et al., 2010). Meanwhile, differences in policies and rules may cause problems when heterogeneous actors collaborate (Christensen et al., 2007). Differing levels of trust, experience, legitimacy and uniformity of understanding of the situation are examples of other factors which have a decisive role in response operations involving new actors (Palm \& Törnqvist, 2008). In terms of frameworks and methods, Bryson et al. (2006) present a framework for cross-sector collaboration in general, emphasising on the type of collaboration, structure, governance, public value, etc. Another framework by Turoff et al. (2004) shows general design principles for a "Dynamic Emergency Response Management Information System” drawn from a literature review of ERSs. In yet another framework for analysing users' needs to information system in ERSs, factors such as information sharing, resource allocation, privacy, and coordination with national resources were found to be important considerations in information system support (Ki Kim \& Sharman, 2006). However, these frameworks are either intended for general cross-sector collaboration purposes or do not include recent changes in ERSs, and thus might not be applicable in this context. 


\subsection{Study context: recent trends in the Swedish ERS}

In 2009 the Swedish government assigned the Swedish Civil Contingencies Agency (MSB) ${ }^{1}$ a mission called "strategy for strengthening the societal resources in coping with emergency situations." This strategy uses complementary actors in collaboration with available professional resources. The current ERS boundary in Sweden is shown in Fig 1. The main professional ERS actors are the police, the fire and rescue services, the ambulance services and the alarm centres. Another recent important group is semi-professionals who belong to occupational categories in other sectors, such as eldercare personnel, security guards, and building technicians who might help the ERS if they receive basic training. Other groups include private persons, volunteers/nonprofit organisations, clubs, and other local community members that, in theory, can assist main actors in emergency situations that range from everyday accidents (such as traffic accidents, building fires, or drownings) to major disasters (storms, flooding, and earthquakes). However, these actors are not yet counted officially as a part of the Swedish ERS and it is not clear how they should communicate with each other and with professional response actors in response operations.

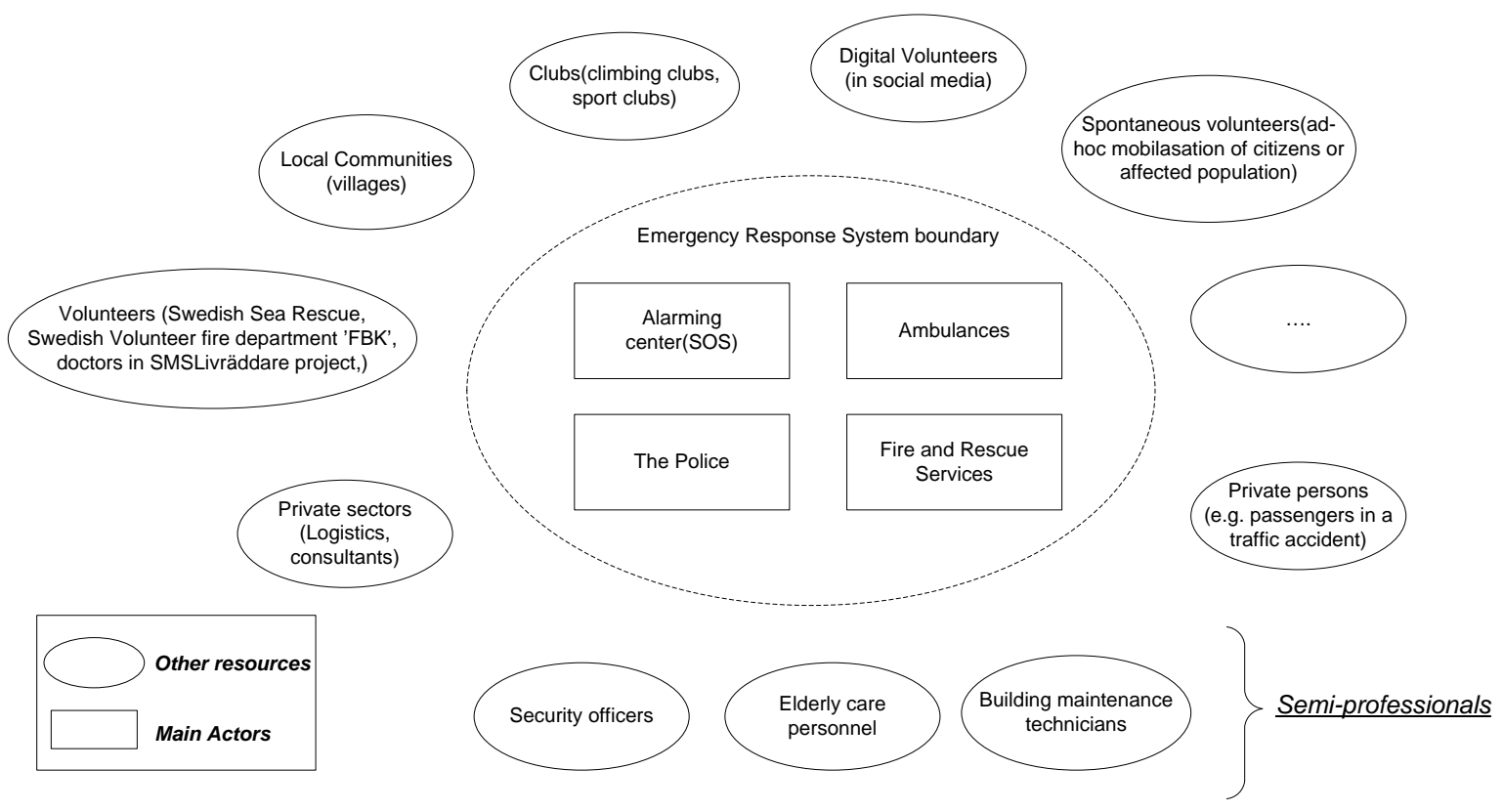

Figure 1. The system boundary of emergency management in Sweden.

In accordance with the above, three recent examples of changes related to Sweden's ERS are:

1) Cooperative use of equipment and existing on-call resources within society (Sambruk), in which oncall semi-professional resources in society are assigned emergency response related tasks in addition to their ordinary duties. For example, in some municipalities, fire and rescue services and social care services share vehicles, equipment and techniques. They also have centralised alarm management for specific types of alarms. In other municipalities, in a project called IVPA (While Waiting for the Ambulance), fire and rescue services collaborate with on-call eldercare nurses and are dispatched in acute health situations when an ambulance is not immediately available or far from the emergency site.

2) Involvement of volunteers in response operations, for example, citizens, non-profit organisations and clubs. As an example, in the SMS Life Saving project, when someone is having a heart attack an SMS is sent to nearby volunteers who can perform cardiopulmonary resuscitation (CPR). In other projects, volunteers in rural areas are trained to do CPR, extinguish small fires, and provide first aid in the case

\footnotetext{
${ }^{1}$ The MSB in Sweden mostly has a supportive role for the ERS at a strategic level. Knowledge enhancement, supervision, and key question are an example of the areas the MSB is active in (www.msb.se).
} 
of heart attacks, traffic accidents and fires. Information systems are used to position them, dispatch them and facilitate their communication with other actors.

3) Permanent co-location of professional responders and support actors who share physical spaces in order to have close communication and collaboration. One example is the inter-organisational collaboration between the police, fire and rescue services, ambulance services, and alarm centres, the Church of Sweden, the Swedish Defence and more, located in a shared physical place called the Safety House in the city of Östersund, in the Jämtland province. Here, information systems have important roles in presenting, sharing and exchanging information about incidents.

\section{METHODS}

The investigation was carried out as a case study using qualitative research methods (Denzin \& Lincoln, 2011) including interviews, participant-observation, and future workshops.

\subsection{Case study research}

Case studies is one of the most common ways of performing qualitative research that seek to study real social, organisational, or political phenomena (Stake, 2000). It has been chosen as the overall methodology in this study, looking at new forms of collaboration between actors in ERSs. The case includes three recent examples of new forms of collaboration in emergency response (the co-location of actors, involvement of volunteers, and cooperative use of resources) in Sweden which reflect the recent trends in ERSs and in the public sector. Case studies can be of an exploratory, descriptive, or explanatory character (Yin, 2012). This study has both exploratory and descriptive elements, as it first seeks to identify important aspects of new forms of collaboration, and then to describe and systemise them within a framework. Data was collected from multiple sources, including literature reviews, interviews, future workshops and participant observation, in order to triangulate the data and produce a richer dataset for analysis. Case study research can be generalizable but to propositions; not to large populations (Yin, 2013). The cases must be replicated and the propositions tested in several cases to produce more generalizable results. This also goes for the framework of this study.

\subsection{Framework development}

The framework was developed in a stepwise procedure :

\section{Step 1: Interviews and focus group and literature study}

The initial framework was grounded in empirical data and is explained in detail in Yousefi Mojir and Pilemalm (2013).This step generally focused on the new forms of collaborations in the Swedish ERS. Data was collected through interviews. Interviews are commonly used in qualitative research to gain an understanding of peoples' experiences and their perspectives (Seidman, 1998). Semi-structured interviews were first conducted with three interviewees from The Swedish Civil Contingencies Agency (MSB) who were working on strengthening the response capacity of the Swedish ERS through new collaborations. The main goal was to gain a strategic-level understanding of how the collaborations were perceived by the MSB. The fourth interview was conducted as a focus group with three security guards from the municipality of Södertälje whose security team supports the fire rescue services by acting as first responders. The purpose was to gain an understanding of how new actors at the operative level perceived new forms of collaboration. Each interview lasted about 60 minutes. They were audiotaped and transcribed for further analysis.

An additional literature review was performed to grasp the whole picture of new forms of collaboration and their related challenges, and to verify the Swedish picture in a general perspective. A literature review is defined as "a systematic search of published work to find out what is already known about the intended research topic" 
(Robinson \& Reed, 1998). Approximately 50 papers, public reports, and project documents all related to the studied case were reviewed.

\section{Step 2: Interviews, future workshop, and participant observation}

To further develop the framework and test its applicability in development of information systems, data was collected from four additional interviews, participant observation activities, and a future workshop on the case of "co-location". The study was conducted at the Safety House and was specifically intended to test the ability of the framework to identify the actors' needs for information system support. The method and the results from the Safety House study have been presented in detail in Yousefi Mojir and Pilemalm (2014).

\section{Interviews}

Interviews were conducted with the project manager, a representative from the police, a representative from the fire and rescue services, and a representative from the Swedish Defence at the Safety House. Each interview lasted about 60 minutes. They were audio-taped and transcribed for further analysis.

\section{Future workshop}

A “future workshop" is one of the methods frequently used in participatory design. It allows users (participants) to develop new ideas and realistic solutions to their work needs (Jungk \& Müllert, 1987). In this case, a half-day future workshop was arranged involving eight actors at the Safety House from the police, the municipalities in Jämtland, the fire and rescue services and the representative from the Swedish Defence. Four participants in the workshop were the same persons as those from the interviews. The future workshop was documented in written notes and was audio taped for transcription.

\section{Participant observation}

Participant observation involves observing a phenomenon in a real-world setting and recording it for scientific purposes (Angrosino, 2007). In this study, researchers conducted participant observation by visiting the Safety House and its physical settings. The observation focused on how different actors shared their work environment. The researcher role was mostly as a participant observer (Creswell, 2013). This means that the researcher did not interfere in actors' activities and did not perform tasks with them, but rather asked people in the setting brief questions about how they carry out their work, including the police, the alarm centre, and the fire and rescue services. In total, 7 persons were included in the participant observation. Three of those had taken part in the future workshop and interviews. The participant observation data were documented through written notes.

\section{Data analysis in step 1 and 2: the construction of the framework}

Data from step 1 were coded in order to shape the framework by applying proper coding methods. Codes are labels or tags that are assigned to a chunk of textual data in order to classify it into a certain category (Myers, 2009). The approach was used to identify important themes in new forms of collaboration. Patterns concerning strengths, weaknesses, and challenges are examples of the themes identified. The initial framework was constructed by categorising the identified themes in terms of important aspects to consider in new forms of collaboration. The knowledge gained from the literature review was used to validate the framework and control whether it was reasonably in line with existing international research. In step 2, the data from the interviews, participant observation, and the future workshop were analysed and the results added to the framework to enrich its existing dimensions. This included clarifying each dimension by providing more examples. The initial framework was also slightly modified. Some dimensions were renamed or combined and a few new added to make the framework more useful. For example, the Competence and Training dimensions were combined, because they were interdependent. Leadership was added as a new dimension, because Safety House actors emphasised it as an important factor in improving collaborations.

The data collection process in step 1 and 2 has been summarised in Table 1. 
Table1: Summary of data collection. The first column shows the methods used in data collection. The next column shows the data source and organisation level. The "Reference" column indicates the name used to refer to the data source in the remainder of the text. The last column contains detailed information about the participants.

\begin{tabular}{|c|c|c|c|c|c|}
\hline Method & Source & $\begin{array}{l}\text { Organisational } \\
\text { Level }\end{array}$ & $\begin{array}{l}\text { Reference } \\
\text { in this } \\
\text { paper }\end{array}$ & Participant(s) & Examples \\
\hline \multirow{8}{*}{ Interviews } & \multirow{3}{*}{ MSB } & \multirow{3}{*}{ Strategic } & Interview 1 & $\begin{array}{l}\text { Works at the MSB with } \\
\text { strengthening the response capacity } \\
\text { in the Swedish ERS at strategic level }\end{array}$ & $\begin{array}{l}\text { Involving new actors such as } \\
\text { semi-professionals to help the fire } \\
\text { and rescue services }\end{array}$ \\
\hline & & & Interview 2 & $\begin{array}{l}\text { Works at the MSB on costs/benefits } \\
\text { analysis of the cooperative use of } \\
\text { resources in the Swedish ERS }\end{array}$ & $\begin{array}{l}\text { To shorten response time in the } \\
\text { case of heart attacks with the help } \\
\text { of new resources }\end{array}$ \\
\hline & & & Interview 3 & $\begin{array}{l}\text { Works at the MSB with using } \\
\text { volunteers actors in the Swedish } \\
\text { ERS }\end{array}$ & $\begin{array}{l}\text { Involving volunteers such as car } \\
\text { and climbing clubs }\end{array}$ \\
\hline & $\begin{array}{l}\text { Södertälje } \\
\text { Municipality }\end{array}$ & Operative & $\begin{array}{l}\text { Interview } 4 \\
\text { (Focus } \\
\text { group) }\end{array}$ & $\begin{array}{l}\text { Three security guards in Södertälje } \\
\text { municipality in Sweden }\end{array}$ & $\begin{array}{l}\text { Collaboration between the fire } \\
\text { and rescue services and security } \\
\text { guards }\end{array}$ \\
\hline & \multirow{6}{*}{ Safety House } & Administrative & Interview 5 & Project manager & $\begin{array}{l}\text { Co-location of main and } \\
\text { supportive actors at the Safety } \\
\text { House }\end{array}$ \\
\hline & & \multirow{3}{*}{ Operative } & Interview6 & Police representative & $\begin{array}{l}\text { The police involvement in the co- } \\
\text { location }\end{array}$ \\
\hline & & & Interview 7 & $\begin{array}{l}\text { Fire and rescue services } \\
\text { representative }\end{array}$ & $\begin{array}{l}\text { The rescue services involvement } \\
\text { in the co-location }\end{array}$ \\
\hline & & & Interview 8 & Swedish Defence representative & $\begin{array}{l}\text { The Swedish Defence involvement } \\
\text { in the co-location }\end{array}$ \\
\hline $\begin{array}{l}\text { Future } \\
\text { workshop }\end{array}$ & & $\begin{array}{l}\text { Operative+ } \\
\text { Administrative }\end{array}$ & $\begin{array}{l}\text { Future } \\
\text { workshop }\end{array}$ & $\begin{array}{l}\text { Representatives from the police, the } \\
\text { fire and rescue services, Swedish } \\
\text { Defence, the Municipality of } \\
\text { Östersund, and the project manager }\end{array}$ & $\begin{array}{l}\text { Analysis of needs of ISs to } \\
\text { improve the co-location }\end{array}$ \\
\hline $\begin{array}{l}\text { Participant } \\
\text { observation }\end{array}$ & & Operative & $\begin{array}{l}\text { Participant } \\
\text { observation }\end{array}$ & $\begin{array}{l}\text { Representatives from the police, } \\
\text { fire and rescue services, and the } \\
\text { alarm centres }\end{array}$ & $\begin{array}{l}\text { Observation of the physical } \\
\text { setting at the Safety House }\end{array}$ \\
\hline
\end{tabular}

\section{Step 3: Adding the socio-technical and participatory design perspective}

In the third step, the framework was placed in the context of information systems development. This was achieved by using socio-technical system theory and participatory design. One of the most sophisticated application of socio-technical system might be in Rasmussens and Svedung's model of socio-technical systems in risk management (Leveson, 2012; Rasmussen \& Svedung, 1997). According to this model and other similar models, e.g., Laudon and Laudon (1999) and Davis et al. (2014), a socio-technical system has several levels or components, including technological, human-factors, work processes, organisational and managerial aspects, economics, law and politics. These, however, are usually researched separately and the results are not connected and analysed collectively. In this paper, to correlate these levels and to relate them to emergency management, five component/levels have been adapted and renamed. Human factors were renamed as 'Actors' and refers to all characteristics and factors related to actors in response operations. Work processes were renamed to 'Task/response operations' to keep the focus on jobs related to response operations at an operative level. Technological components remained unchanged and are named as 'Technology' in the framework. Organisational, managerial and economical aspects are renamed to 'structure/organisation' since they are all related to and stem from organisations and their structures. Finally, 'Environment/Context' was used to refer to legal, political and environmental aspects of response operations. Using inspiration from participatory design, actors and their roles and tasks were also located at the centre of the framework. This simply means that actors and their needs are in focus and other categories are dependent upon them. Figure 2 shows the different contributions added to build and develop the framework in the third step. 


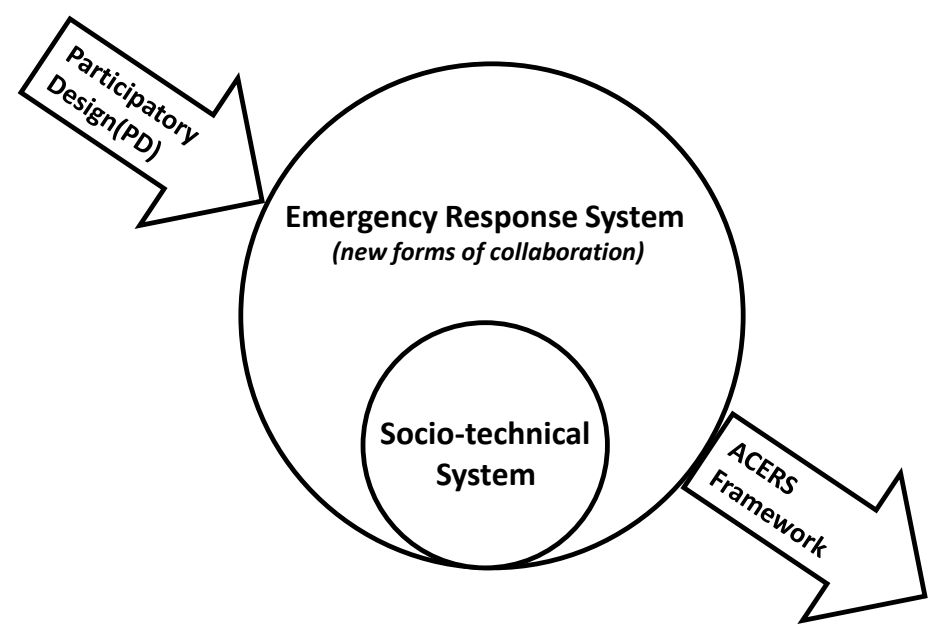

Figure 2: Combining participatory design, socio-technical system theory and the ERS context in the ACERS framework

\section{RESULTS AND ANALYSIS}

The dimensions of the framework are shown in Figure 3. In the results and analysis section, the dimensions are described, and then suggestions of how and why to apply the framework is provided, with a special focus on the information systems development process.

\section{Actor-Centered Emergency Response System (ACERS)}

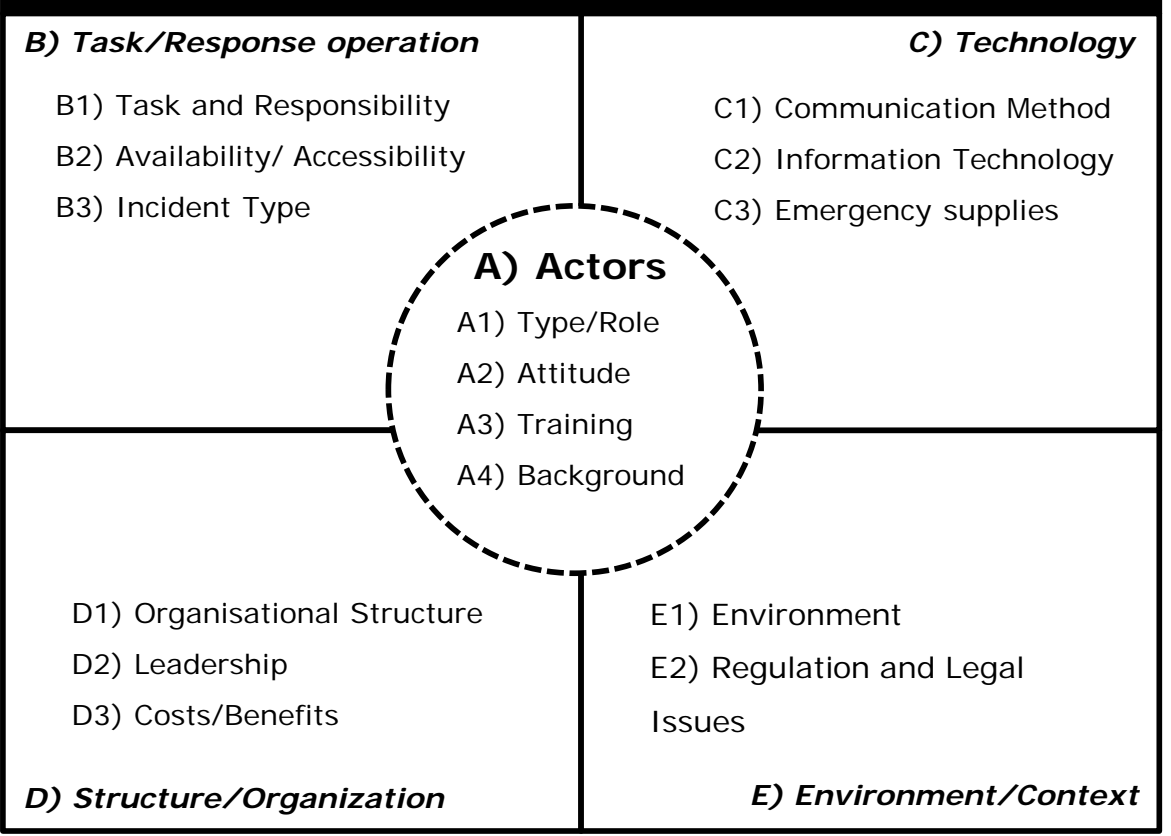

Figure 3: The ACERS framework, displaying parent dimension and sub-dimensions

\subsection{The ACERS framework}

The name ACERS (Actor-Centred Emergency Response Systems) was chosen to reflect the centrality of actors (users/stakeholders) in ERS analyses. Figure 3 above represents the result of applying socio-technical system 
theory and participatory design to the framework. To make the framework easier to understand, dimensions are grouped in five main categories derived from components of the socio-technical system thinking. These are called parent dimensions: Actors, Task, Technology, Structure, and Environment. “Actors" is located in the centre, since participatory design emphasises that system analysis and development should be conducted together with actors, taking them as the point of departure. Each parent dimension has other sub-dimensions (e.g., Leadership, Communication methods, etc.) which are suggested units to study in new forms of collaboration. These have been categorised and are shown inside the respective parent dimension. The five parent dimensions are referred to as $\mathrm{A}, \mathrm{B}, \mathrm{C}, \mathrm{D}$ and $\mathrm{E}$ in the ensuing text:

\section{A) Actors in the centre}

This part of the framework is used to analyse and formulate valid and reliable characterisations of actors in ERSs, i.e. those who perform response operations in emergency management. There are many dimensions of actors that can be investigated. However, their identity (type, roles), their attitudes towards their task/job, types of training they have or need, and their relevant background have been identified as especially important aspects especially when performing needs analysis. The other parent dimensions are located around Actors, which means they should be studied in connection with actors and with respect to the results of analysis of the Actors dimension.

\section{A1: Identity - Type and Role}

This dimension describes the roles of actors, and particularly potential new actors, in ERSs. The compilation of the interviews from the MSB, security guards, and the Safety House show that different types of actors take part in new forms of collaboration in the Swedish ERS, depending on their identity and characteristics. The first group is semi-professionals: persons whose primary profession is not to respond to emergencies but who can support the ERS on the basis of their primary profession provided they are given additional training. Eldercare providers, guards, taxi drivers and building technicians are examples of occupational categories that, in theory, can assist professional response organisations.

Volunteer groups are a second type of actor that comes in various forms and sizes, such as the Swedish Sea Rescue Society, the Red Cross, the Swedish Climbing Federation, small clubs, local sports groups, and general civilians. Volunteer groups can help professional resources to focus on more complicated tasks by taking care of easier, but still time-consuming activities that do not demand any specialised professional skills, as interviewee 3 explained. Interviewee 6, a police interviewee at the Safety House, sees self-deployed (spontaneous) volunteers as an important source of help, especially in the case of searches for missing people.

Private persons or non-professionals (also bystanders or laymen) is yet another group of actors who may find themselves suddenly at the emergency site without any previous intention to perform a response operation, as defined by the MSB interviewee in interview 1 . If they are aware of what they should do in a particular situation, they can intervene in an effective way; for example performing first aid in a traffic accident or containing small fires before they spread.

New actors may not only be categorised as semi-professionals, volunteers, or laymen, but also according to the different roles they play. Three interviewees from the MSB mention new actors' different roles as: (1) First Responders who perform response operations directly (e.g. providing first aid); (2) Assistants who lend a helping hand to professional first responders; and (3) Supportive actors who facilitate the work for other actors (for example, by providing transportation and supplies). The focus group interviews with security guards (interview 4) show that they mainly have an assistive role. For example, they send information (observations of the accident scene) to the fire and rescue service or provide keys to enter buildings.

\section{A2: Attitudes}

Interviewee 1 (MSB) felt that perceived fear of acting in an emergency was a major obstacle in carrying out response when new actors are alone or do not have the proper skills. For example, most people believe that a fire is not controllable and that when a house is on fire it will burn down. With a few hours of training, people can 
learn how to control and contain the fire before it spreads. The interviewee also implied that semi-professionals do not always feel good or certain when they operate in fields other than their own. The interviewee also indicated that trust was an important factor in collaboration between actors. All interviewees at the Safety House also mentioned that they would be more comfortable cooperating with someone who they already knew and trusted or had shared experiences or training with.

All interviewees who participated in interviews and the workshop at the Safety House acknowledged that actors involved in the co-location are quite positive regarding this new setting as a work environment. However, they also identified ambiguities in the goals and visions within new forms of collaboration that may cause resistance to change, mostly related to the conflict between actors' existing roles and tasks and the new ones. For instance, they think it is not still clear how actors should prioritise their tasks in the new forms of collaboration and who the decision-maker is.

\section{A3: Training and preparedness}

MSB interviewee 1 pointed out that actors' extent and type of training greatly impacts their participation in response operations. Training in firefighting, first aid, and cardiopulmonary resuscitation (CPR) are examples pointed out in the interview. With extra basic training, semi-professionals can act as a first responder in the early stage of an incident using skills in first aid, uses of a fire harness, etc. Members of the general public can be taught what to do and not do when one arrives at an emergency scene, starting in elementary school. The continuity of training and exercises keeps new actors prepared for action.

At the Safety House, training for collaboration was stressed, especially by the project manager in interview 5 . This includes handling information exchange and knowing each other's organisational tasks and responsibilities. All interviewees at the Safety House claimed that this type of training could improve collaboration among different actors who come from different fields performing different tasks.

\section{A4: Background}

There are a number of background characteristics that may affect users' roles and tasks in ERSs. Qualifications, experience, age, physical and cognitive capabilities and motivation are some characteristics named by the MSB interviewees. Members of the general public do not usually have sufficient qualifications to intervene in an emergency situation. They need additional education and information to be able to respond properly. Other volunteers may already have specific qualifications (e.g. rock climbing or mountaineering clubs). These volunteers can help other actors in search operations in mountains and places that are difficult to access. Actors' background and qualifications has a decisive role in determining what they can do and what type of task they can be given.

\section{B) Task - Response Operation}

The second parent dimension is labelled response operation (Task). The sub-dimensions (or units of analysis) defined in this category are: actors' task, availability/accessibility, communication methods and incident type. This part of the framework serves to investigate task elements or structures, as well as the organisational goals that are associated with overall response tasks and that are also important factors required to accomplish a given task.

\section{B1: Task and Responsibility}

Interviewees 1 and 2 at the MSB concluded that there are different standby (on call) resources available at the municipality level in Sweden who can initiate response operations before the arrival of main actors at the scene. For example, in case of building fires, maintenance personnel can start simple responses such as extinguishing small fires before spreading. They may also save lives by performing basic life support before the fire rescue service arrives and can start more advanced response tasks such as smoke diving. All interviewees in the focus group interview claimed that security guards help fire rescue services enter burning buildings more quickly because they usually know the entrances and have the keys. They can also observe the incident and send vital 
initial information to the fire and rescue services. Interviewee 2 at the MSB also referred to the "SMS Life Saving” project (http://www.smslivraddare.se/) in Stockholm, in which volunteers near the accident scene are sent alarms at the same time as main actors, through alarms indicating cardiac arrests. Volunteers in completely different roles may also support or performs tasks such as cleaning up the environment after oil spills or taking care of victims' relatives.

With respect to responsibilities (i.e., formal expectations from actors , accountability and having control on decision-making), almost all participants in the future workshop at the Safety House identify ambiguity in the news tasks and new collaborations, because these responsibilities and the formal expectations of actors in response operations have not yet been determined and formalised. Participants also believed that decisionmaking and command and control hierarchies in response operations were not clear in this type of collaboration.

\section{B2: Availability and Accessibility}

MSB interviewee 3 described different ways to access and to activate volunteer actors in ERSs. Volunteers can be activated upon request by professional response actors, or volunteers may evaluate the situation and activate themselves. The interviewee also explained that there are people who are interested in volunteering, but there is no clear method that prescribes how they can contact professional actors and take part in response operations. Self-deployed volunteers who are available for missing person searches were mentioned as an example by interviewee 6 at the Safety House. MSB interviewee 2 confirmed that many semi-professional and on-call resources available in society are poorly integrated. They can support the ERS, but it is not clear how they should work with professional actors since there are yet no established agreements, contracts, and financing routines.

\section{B4: Incident Type}

All MSB interviewees emphasised that new actors who act as first responders will become increasingly important in the case of first aid in incidents such as fires, medical incidents requiring first aid or cardiopulmonary resuscitation (CPR), and traffic accidents. For example, time is vital during a heart attack, and if somebody performs CPR in the first 15 minutes there is a high chance the victim will survive. Fires are more controllable if somebody starts to extinguish them in the initial phase. In forest fires, volunteers can help to look for missing persons and also provide transportation, vehicles, or appropriate tools. There are, however, incidents that new actors should not intervene in if they are unaware of the possible consequences. Neck fractures, hazardous pollution emissions, and terrorist attacks are examples of such incidents. Moreover, some incidents take place in forested or mountainous areas where access to the scene is difficult. Interviewees at the Safety House said that they often need to involve the local population to find the exact position of the incident, because it is difficult to find it solely with the help of technology.

\section{C) Technology}

The technology parent dimension has the following sub-dimensions: communication methods, emergency supplies and information technology. This part of framework aims at identifying the types of tools and technologies that actors are already using or will need in the future.

\section{C1: Communication Method}

Several interviewees at the Safety House stated that transferring audio and images between different actors facilitated their situational understanding. It was stressed both in the future workshop at the Safety House and in the focus group with security guards that good communication is the foundation for good collaboration and can support coordination between actors. However, there is no clear method available regarding how new actors should communicate with professional response organisations and with each other. Some of them use radio, and others use mobile phones to contact to fire and rescue services. There is interest in integrating communication systems to help to speed up communication and decision-making. Interviewees from the MSB mentioned Sweden's Rakel system, which is a national digital radio communication platform, as an option for 
communication between new actors and professionals. They also pointed out the SMS services that are used in the "SMS Life Saving" project. Even local radio stations can be used to notify many people at once.

\section{C2: Information Technology (IT)}

The MSB interviewee 1 mentioned that IT can facilitate information exchange between actors in response operations either to gain information about incidents or to disseminate information to others about the incident. Therefore, it can facilitate collaboration at a general level. Interviewees and future workshop participants at the Safety House noted that IT solutions can facilitate situational understanding of the incident and create an integrated infrastructure for sharing information between different actors. At the same time, they noted the difficulty in information sharing, distribution and dissemination due to the current lack of appropriate geographical mapping systems. In general, the type of information actors, and particularly new actors, need depends heavily on the type of operations they perform and their roles in these operations.

\section{C3: Emergency supply}

The focus group interview showed that inappropriate equipment created difficulties in response operations. The security guards complained about the drawbacks of non-portable radio systems. They had problems sending information to the fire and rescue services, so they had to use mobile phones. The MSB interviewees mentions the SALSA project in Stockholm, in which taxi drivers are equipped with defibrillators in their vehicles to give aid to people experiencing heart attacks. Actors at the Safety House project also wished they had better, more flexible equipment that is better suited to their new form of work in response operations, such as portable map devices. All interviewees stressed the usability of good equipment and its impact on response operations when such equipment is designed according to actors' tasks and needs.

\section{D) Structure and organisation}

The fourth parent dimension focuses on the structure and organisation that actors have or work in. The focus of this dimension is at a higher organisational level than the other dimensions. Organisational structure, leadership, and costs/benefits of response operations are the sub-dimensions and units of analysis.

\section{D1: Organisational Structure}

MSB and the security guard interviewees pointed to different structures for actors either as a part of organised structures (e.g. Red Cross volunteers, sport clubs, or climbing clubs) or unorganised structures (e.g. the general public). Safety House interviewee 5 mentions self-deployed volunteers as another structure for volunteers, such as the ad-hoc mobilisation of individuals and groups who help the police in missing persons search operations.

\section{D2: Leadership}

At the Safety House, actors meet all together in a shared room to make decisions regarding the required response to an emergency situation. At the same time, the actors pointed out a problem in the command and control of response operations, because it is not clear who is responsible for controlling the response operation and who has priority in decision-making.

\section{D3: Costs/benefits}

Interviewee 1 mentioned that it is important, especially at a strategic and political level, to analyse and present the costs and benefits associated with new forms of collaboration in order to motivate and encourage them. MSB interviewee 2 gave an example in which 42 persons were estimated to have been saved instead of 26 when fire and rescue services were used together with health care personal in response operations in cases of heart attacks. However, if more lives are to be saved, more resources will need to be invested and more equipment is needed, which in turn is associated with increased costs. Almost all interviewees from the Safety House agree on the benefits of saving time in communication and decision-making. However, both benefits and costs for information systems, equipment and resources should be analysed and calculated with regard to new forms of collaboration. 


\section{E) Context}

The fifth parent dimension of the framework explores the ERS environmental conditions and their effect on task completion. Work environment and legal issues are dimensions which should be taken into account.

\section{E1: Work environment}

At the Safety House, participant-observation showed how the work environment has substantially changed as compared to the past. Different actors share the same building and sit very close to each other. They can meet together immediately if needed. They have a shared decision-making room. Actors at the Safety House reported that this new setting allows users to know each other's tasks and responsibilities better. On the other hand, this may also cause problems, because actors may break the rules in some cases because they may not know the rules about the information sharing and confidentiality in their respective organisations when they talk about their jobs, tasks, and work environment in informal situations (e.g. during lunch breaks).

\section{E2: Regulations and Legal issues}

MSB interviewee 3 stated that legal problems arise on many occasions. Since these types of collaborations are relatively new, it is not yet clear what the Swedish laws have to say with respect to responsibility, restrictions, job contracts, financing, job safety, and tasks of new actors in response operations. This relates to what new actors are legally or ethically allowed to do or not do. Specifically, it is not clear under Swedish law what types of data they are allowed to access and what first aid measures they are allowed to perform. Even current professional actors in the ERS do not always have clear rules about information sharing in the case of collaboration with others. For example, all interviewees at the Safety House claimed that the main actors had problems in sharing information among one another, specially videos and photos of incident scenes, due to the ambiguity in rules about data confidentiality at the different organisations.

\subsection{International relevance of framework - results from the literature review}

ERSs in different countries probably have many similarities, including roles, resources, training, technology, and equipment needs since they all deal with emergency situations with the goal to save lives and minimise environmental damage. The literature review sustains this assumption by showing that there are similar efforts worldwide that overlap with the dimensions A, B, C, D, and E in the framework. In connection to dimension A, 'Actors', there are several studies that discuss different roles and types of new actors as volunteers, bystanders and semi-professionals when regular resources available are insufficient (Venema et al., 2010; Waugh \& Streib, 2006). Type of training (Fischer et al., 2011) and actors' experience (Palm \& Törnqvist, 2008) in establishing new forms of collaboration are also mentioned as important factors. In connection to dimension B, 'Tasks', there are studies that point out new actors' tasks in response operations such as acting as first responders to perform basic life support, collecting food and supplies, and providing of medical and emotional aid (Barsky et al., 2007; Lindell et al., 2001; Quarantelli, 1994; Valenzuela et al., 2000; Weinholt \& Andersson Granberg, 2013). Moreover, type of incidents (e.g. cardiac arrest and drowning) in which new actors can be involved has been discussed as an important factor in the literature (Valenzuela et al., 2000; Venema et al., 2010). In connection to dimension C, 'Technology and equipment', Jack (2005) argues for the importance of equipping first responders who arrive first at the emergency site. Human factors such as skills in communication with other actors and sense-making have been highlighted in emergency response and design of proper equipment (Schraagen \& Ven, 2011). In connection to dimension D, 'Structure and organisation', differences in policies and the presence of heterogeneous actors (Christensen et al., 2013), legitimacy, trust, and uniform situational understanding (Palm \& Törnqvist, 2008) have been named as important factors that should be studied and considered in new forms of collaboration. In connection to dimension E, 'Context', legal issues and conflicts in policies and rules in organisation in the categorisation of tasks and responsibilities have been pointed out as problems in the crosssector collaborations when actors come from different distinctive organisations (Christensen et al., 2013). 


\subsection{How to apply the ACERS framework: general principles}

The framework is intended to provide support in analysis of new forms of collaboration in ERSs: for example, to understand collaboration, actors' tasks, and related challenges and needs. It will help also to consider various important aspects such as e.g. laws, competences, and leadership, and not to overlook them. In particular, it can be used in new collaborations between professional actors and new actors. There is no need to focus on all dimensions for every project context; on the contrary, the importance of the dimensions will probably vary depending on context. It is also important to be aware that there are no fixed relations between the dimensions, because relations may differ depending on the context. Nevertheless, there is a visible connection in the framework, in which the centre of the framework (Actors) is strongly connected to all other dimensions. In the framework, the point of departure should thus always be the Actor parent dimension. This will ensure that actors are not overlooked in the analysis. For example, actors' tasks, the types of incident they participate in, and the legal issues they may face should all be discussed, taking into account the actors' characteristics such as type, role, background and training.

\subsection{Applying the ACERS framework to information systems development}

The information systems development processes can, in a general sense, be said to consist of the phases of analysis, design, implementation, testing/validation, and maintenance (Avison \& Fitzgerald, 2006, p. 31). Participatory design emphasises on the involvement of the users, especially in the early phases. This section describes how the framework can be used in information systems development for ERSs from a socio-technical/ participatory design perspective.

\section{Organisational and context analysis}

The purpose of the analysis phase is to analyse systems, a part of system, or related phenomena; this may be the whole organisation, a process, a change, a work environment, a function, etc. (here the focus of analysis is new forms of collaborations).Here, it is important to gain an initial understanding of the relevant ERS context, without involving the ACERS framework, in order to get a brief overview of the actors, key organisations, the types of collaborations involved, and the information systems that are requested or are to be developed. Subsequently, it is important to go through all the dimensions and choose the dimensions that are most appropriate to the current project. The framework can then be used to perform the stakeholder/actor analysis. In this analysis, different actors should be identified and categorised, using the identified dimensions as a point of departure. According to certain participatory design approaches, all stakeholders who are affected by the information systems under development should be involved. In an ERS, this may include main response actors (e.g. fire and rescue services, the police, ambulance services, and the alarm centres), semi-professionals, volunteers, managers in the respective organisations and municipalities, administrators, economists and jurists. One way to achieve such involvement is to look at all the relevant dimensions in the framework and identify those actors that have information and can help explore these dimensions. For example, the framework apparently shows the need to involve persons who know about laws or leadership, if these dimensions are counted as relevant aspects of a project. In the next step, it is important to collect detailed data about the framework dimensions that have been identified as relevant. This can be done by involving the identified actors, formulating relevant questions, and using appropriate data collection methods (such as interviews, observation, or surveys). In this phase, existing principles, rules, policies, and workflows are analysed for each relevant dimension in order to understand the context.

\section{Needs analysis and requirements specification}

The needs analysis identifies users' needs in relation to information systems in their work environment. In line with the principles of participatory design, all actors who are potential end users of the intended information system and have a role in new forms of collaboration should be involved in this phase. These actors may include volunteer groups, the general public, and members of organisations. For example, since the fire and rescue service, police, alarm centre and non-profit organisations at the Safety House participate in new forms of collaboration, they all should be involved in the needs analysis process. As another example, both security 
guards and the fire and rescue services in Södertälje should be involved in this project context. The primary endusers are most likely clear from the beginning when launching an information systems development project. Others can be selected from the results of the actor/stakeholder analysis. Needs analysis can be performed using the framework to determine interviews, observations, case studies, future workshops, and so on. The framework may help to more effectively and comprehensively formulate templates and questions and to form case studies so that they cover all relevant dimensions. The relevant dimensions should be discussed in the needs analysis process, in order to find out how they are related to users' needs and how they impact these needs. For example, the Communication dimension should be discussed to identify users' needs for communication related information systems. The Law dimension should be discussed in order to understand how different laws and policies may affect or inhibit users' needs, for example as related to information exchange. The Organisational Structure dimension should be discussed in terms of how different structures influence users' needs (e.g. government vs. governance patterns) and so on.

The identified needs should be also connected to the results from the organisational analysis so they can be categorised and prioritised. Here, the data collected in the organisational analysis and needs analysis should be compared for each relevant dimension to see how needs are connected to organisational goals, identified challenges and actors' tasks. In the subsequent specification of requirements, this helps to formulate needs in terms of information system requirements. When it comes to prioritising requirements, the framework can be used in the development processes to identify potential problem in satisfying different requirements. For instance, if one requirement may not be feasible due to existing laws, a conflict that can be identified quickly by looking at the legal dimension. Such requirements can either be omitted or revised in order to comply with all relevant dimensions in the framework.

\subsection{Applying the framework to later phases of information systems development}

The framework does not explicitly contribute to coding and technical implementation of information systems. Its potential contribution is implicit because the implementation phase is based on the results from previous phases in the system development process. The framework may also be used in the testing and validation phase. Here, system developers review the functionality of the designed information system to find out whether it has been built according to the relevant framework dimensions and the data collected in the analysis phases. It therefore helps to identify system functionality problems and whether the information system as designed does or does not satisfy users' needs. For example, does it take the identified legal problems, response actors' education levels, and organisational structure into account? The validation process should be done for all relevant dimensions before opening the newly designed information system for use. The analysis performed for some framework dimensions—-such as actors' education, background and tasks—can also yield knowledge that may be helpful in designing appropriate training programs and guidelines for new actors in later phases of information systems development.

\section{DISCUSSION}

To overcome public challenges in societies, a recent trend in the public sector has been to establish new forms of collaboration in order to compensate for resource shortages and budgetary cutbacks (Goldsmith \& Eggers, 2004; O’Leary \& Bingham, 2009). This includes, for example, cross-sector collaboration, optimised use of existing resources, and involving new actors such as volunteers and civilians. In the specific case of ERSs, studies have highlighted the demand for new actors and volunteers when the regular resources available for rescue and response are insufficient (Waugh \& Streib, 2006). For instance, after Hurricane Katrina, it was claimed that the downgrading of volunteers' role in crisis management led to inadequate treatment of injured people (Tierney et al., 2006). Volunteers who participate in disaster management have been shown to be able to perform a variety of tasks, such as debris clearing, collection of food and supplies, provision of shelter, offering of assistance, and provision of medical and emotional aid (e.g. Barsky et al., 2007; Lindell et al., 2001; Quarantelli, 1994). The positive impact of bystanders acting as volunteers has been shown to save lives, e.g. in drowning incidents and 
resuscitation (Venema et al., 2010). Sund (2006) also showed how the use of semi-professional actors can improve the overall quality of response operations, especially in cases where the response time is crucial, such as cardiac arrests.

Despite its clear potential benefits, involving new actors and cross-sector collaborations also means that ERSs are becoming increasingly complex systems with new challenges. Problems such as the categorisation of tasks, responsibilities, structures, competences, legal issues and others have been pointed out by researchers such as Pilemalm et al. (2013). Yousefi Mojir and Pilemalm (2014) argue that the network governance at the Safety House, with high degrees of informal interaction, contrasts with bureaucratic structures and causes ambiguities in responsibilities, goals and visions and creates many legal and ethical obstacles, such as data confidentiality. Another Swedish study shows how differences in mandates, cultures and professions can complicate inter-organisational collaboration in emergency management (Ödlund, 2010). Yet another study discusses how involving volunteer actors in the UK public sector can generate risks for the political system and government if trust is not managed correctly (Burt \& Taylor, 2004). In summary, while changes in ERSs have demonstrated both benefits and potential complexities, there is a lack of corresponding studies about how these complexities can be analysed and managed. To fill this gap, the ACERS framework presents 15 aspects to consider when introducing new forms of collaboration in ERSs.

\subsection{Growing need to develop information systems for new forms of collaboration: initial experience from testing the framework}

In any information systems development process, it is usually perceived difficult to identify users' real needs (Iivari et al., 2010). It has even been claimed that about 85\% of development projects fail because of insufficient or inadequate analysis of user needs (Boehm \& Papaccio, 1988; Young, 2002). The challenges are especially apparent when the user group is heterogeneous and perhaps only partly identified, e.g., in new forms of collaboration.

One way to address such challenges is to apply a socio-technical approach in which technical features of the system and social features of the work are strongly interconnected (Reddy et al., 2003; Walker et al., 2008) . Another approach that has been frequently emphasised is the active participation of users in information systems development processes (Kensing \& Blomberg, 1998; Swanson, 1974). Therefore, the ACERS framework was developed with inspiration from socio-technical system theory and participatory design to enhance user needs analysis. The framework takes its point of departure in actors and end users. With inspiration from participatory design, it was also suggested that the involvement of users in information systems development processes should be emphasised when using the framework.

The framework has been initially tested in analysing actors' needs at the Safety House (Yousefi Mojir \& Pilemalm, 2014). First of all, the framework was deemed beneficial in revealing the problem of involving important stakeholders when a few dimensions within the framework could not be investigated because the users did not have any good information about them. For example, the cost/benefit aspects of new ways of organising response operations could not be analysed. This is not surprising, since end user actors at the operational level do not usually have influential information about cost aspects. However, because of its importance, this dimension should be considered at the strategic level by involving stakeholders from other levels of the involved organisations who have access to the relevant information. Thus, the framework could facilitate the involvement of actors in the development processes by selecting those who possess knowledge about the dimensions selected in the framework. Dimensions such as leadership and organisational structure also require investigators to turn to higher organisational levels and involve stakeholders with access to the relevant information. In other words, the framework was perceived to help to rather quickly identify the gaps that must be covered in the subsequent development process. Without the framework, the analysis might remain more rudimentary and miss certain stakeholder groups and dimensions, a mistake that could ultimately lead to less effective information systems.

The framework also initially perceived to help the formalisation of using participatory design in information systems development at the Safety House. For example, the framework enabled data to be collected quickly, easily, and effectively since the points of departure were already explicitly stated in the framework and did not 
need to be identified from scratch. Interviews and future workshop scenarios were designed based on the framework dimensions. Questions could be formulated comparatively quickly, since they were connected to dimensions within the framework. The data categorisation was easier, since each dimension within the framework had its own definition and exemplification that could be reused in the analysis. Therefore, using the framework was felt to save time and resources in the Safety House case study.

However, it was initially difficult to use the framework to select the relevant dimensions because of insufficient knowledge about the new setting. An introductory session with the project manager before data collection helped to identify irrelevant dimensions. Consequently, irrelevant questions in interviews, the future workshop, and participant-observation were removed. Another limitation concerns the multiple and sometimes subjective interpretation of dimensions, which can lead to overlaps between the dimensions in some cases. For example, dimensions of task and role clearly overlap in several respects, while in the framework they are presented as two separate dimensions. To address this, it is better to focus on each dimension and the information that is relevant to each dimension. Certain redundancies are inevitable. There is also the risk of bias, as system developers might become too dependent on the framework and produce an analysis that is incomplete or inadequate, neglect data not associated with any dimension, or miss potential new dimensions. Therefore, users' ideas, answers, and observations that are not directly connected to the framework should also be considered, in order to avoid the risk of missing new dimensions.

\subsection{ACERS framework: validity and applicability in other domains}

The ACERS framework is based on a limited data set from the Swedish ERS, grounded in data from the MSB about new forms of collaboration in the Swedish ERS at a strategic level, co-location at the Safety House, and the cooperative use of security guards. Following the completion of this study it has been subsequently applied to the cooperative use of resources in Nyköping and the involvement of volunteers in rural areas in Medelpad. Using the framework in these projects demonstrated much the same benefits as its application at the Safety House, thus further confirming the benefits of using the framework.

As was shown in the result section of the paper, there are different international studies that overlap with the dimensions in the ACERC framework. The ERSs in different countries probably have many similarities in roles, resources, technology use, incident type, etc. The literature review thus indicates the applicability of the framework to ERSs in other countries, either directly or with adaptions. In an even wider perspective, the recent challenges in ERSs can be seen as an instantiation of related challenges in the public sector. The framework could therefore potentially be adapted to other cross-sector collaborations to develop information systems based on actors' needs in the new settings. Furthermore, the framework is based on data, which mostly concerns everyday and frequent accidents. However, as Quarantelli (2000) argues, despite both quantitative and qualitative differences between everyday incidents and large disasters, research and development in different types of emergencies can lead to cross-fertilisation of ideas and answers. Thus, the framework could be beneficial, perhaps with some changes, in disaster management, due to the similarity in resources, roles, and IT support systems. Finally, in this study the framework was targeted specifically at information systems development processes. However, it can also be used for more preliminary and general purposes of analysing new forms of collaboration in ERSs (e.g. performance analysis), and in the public sector, since it helps to understand the nature of the collaboration and its challenges.

\subsection{Framework potential for participatory design approaches}

In participatory design, several scholars has pointed out several challenges usually associated with the approach (Besselaar, 1998; Cavaye, 1995; Graham et al., 1998; Karlsson et al., 2012; Oostveen \& van den Besselaar, 2004). They point out lack of formalisation, effectiveness and efficiency in the PD sub-processes, problems in identifying proper users, and in involving important stakeholders. As a result, they argue that participatory design has been mostly an academic approach with infrequent use in practice and mostly applied to small parts of organisations resulting in small stand-alone IT products. The approach has been reported as difficult to use in large scale because it is difficult to involve all groups of heterogeneous users in the development process (Kyng, 2010; Pilemalm et al., 2012; Pilemalm \& Timpka, 2008). The need to modify participatory design approach to 
address these challenges has been pointed out repeatedly (Balka, 2006; Besselaar, 1998; Kyng, 2010; Pilemalm et al., 2015)

In this study, the framework has been developed specifically for cross-sector collaboration, involving volunteer and new actors in ERSs. However, other projects in which collaboration and involvement of heterogeneous actors are in focus might also benefit from it. Using the framework at Safety House supported the identification of important stakeholders who were not incorporated in the analysis process from the beginning. It also helped to involve a more appropriate set of stakeholders in the analysis process by choosing those stakeholders to cover identified relevant dimensions in the framework. Finally, the framework supported the formalisation of interviews, future workshops, and participant observation in the data collection processes. It is possible that, more developed and standardised versions of the framework behave similarly in other participatory design projects specifically where involving heterogeneous stakeholders is important. It may thereby have the potential to contribute to the improvement of participatory information system development in general. Some of its dimensions such as legal issues, actor's role, and communication might be used directly since they are general whereas others such as emergency supplies, incident types are more specific to ERSs and would need adaption. If the framework is demonstrated to save time and resources and to increase the accuracy in organisational and users' needs analysis in the early phases of participatory information systems development, this could enable development efforts to progress to design and implementation phases more effectively and as a result it would be possible to achieve a final product. Standardised versions of the framework might thus address general challenges in participatory design and contribute to providing its inherent benefits even in complex contexts.

\section{CONCLUSIONS AND FUTURE WORK}

Public challenges such as cutback in budget and resources, the global climate change which has resulted in large scale incidents such as storms and forest fires, global epidemics and pandemics, the emergence of extremist groups and new threats have put huge strain on emergency management organisations in contemporary society. This has further been boosted by rising public civilian expectations on governments for better service delivery and the long distances between response actors and people in depopulated rural areas due to urbanisation, for example in Sweden. As a consequence, ERSs are currently under extreme pressure and need to be re-organised in order to be more effective and create redundancy in societal systems. One recent trend to cope with the challenges involves other societal resources and creating new cross-sector collaborations. However, the increasingly broad set of heterogeneous stakeholders in the new forms of collaboration in its turn introduces new challenges to be dealt with. Legal issues, ambiguities in actors' tasks in the new setting, job related matters such as the need for new insurances and contracts, and the difficulty to determine the actors' needs of proper ISs support are some examples. Therefore, new forms of collaboration must be analysed and understood thoroughly to develop them successfully.

This study contributes to ERSs IS development by providing a conceptual framework for the analysis of new forms of collaboration in ERSs. In a more general sense, the study may also contribute to enhance participatory information systems development by providing a possible means to address the lack of formalisation in participatory design approaches in early design phases. Initially applying the framework at the Safety House showed different benefits such as revealing important but absent actors in the development process. The framework also enabled the system developer to form data collection and data analysis processes based on having the dimensions in the framework as the departure point. The framework also showed some difficulties and limitations such as the risk of bias if developers are bound solely to the framework. Multiple interpretations of dimension and overlaps between dimensions were some other difficulties.

For future research, the framework should be tested in other real-life cases, both for improving it and for validation purposes. Further development of the framework might help to make it more standard, flexible and accurate to be used in a wider range of new forms of collaboration in ERSs. In a longer perspective, it would be possible to compare the results from using the framework in multiple cases and to formalise and follow the same 
format in the case/framework analysis. As a result, it might be possible to determine similarities and differences among news forms of collaboration in ERSs and theorise about them and their related challenges. In the longterm perspective, this could contribute to more effective introduction and implementation of changes when reorganising Swedish and international ERSs.

Beyond ERSs, the framework may also be used with adaptations to other parts of the public sector where crosssector collaborations, collaboration with civilians and volunteer groups, and new forms of network governance are in focus. Examples may include e-government in which citizens and authorities collaborate and New Public Management strategies that often involve the private sector and non-governmental organisations in the delivery of public services. As indicated above, yet another trace of research includes the adaptation of the framework to a more standardised format to be applied in participatory design projects in general, for more effective early development of ISs. The framework might at the same time help to return to PD fundaments and derive its main benefits even in complex environments with heterogeneous actors.

In the next step, the framework will be the point of departure for identifying and analysing new forms of crosssector collaborations and the cooperative use of resources with proper IT support in a project in the municipality of Norrköping. The aim of the project is to involve semi-professional resources such as building technicians, security guards, and elderly care personnel in emergency situations and support them with mobile applications and other IT tools. The actors may be available sooner than professional response resources because they are on patrol in the municipality. In the project, the framework will be used from the initial development phases; thus providing a good opportunity for framework validation and improvement. The framework will also be tested in the subsequent phases (design and implementation) of the participatory IS development in order to evaluate the framework's potential in adding formalisation to the participatory development processes.

\section{REFERENCES}

Agranoff, R. (2007). Managing Within Networks: Adding Value to Public Organizations. Georgetown University Press.

Agranoff, R., \& McGuire, M. (2010). Collaborative Public Management: New Strategies for Local Governments. Georgetown University Press.

Alter, C., \& Hage, J. (1993). Organizations working together. Sage Publications.

Angrosino, M. (2007). Doing Ethnographic and Observational Research. SAGE.

Avison, D., \& Fitzgerald, G. (2006). Information Systems Development: Methodologies, Techniques and Tools (4 edition.). London: McGraw-Hill Higher Education.

Balka, E. (2006). Inside the Belly of the Beast: The Challenges and Successes of a Reformist Participatory Agenda. In Proceedings of the Ninth Conference on Participatory Design: Expanding Boundaries in Design Volume 1 (pp. 134-143). New York, NY, USA: ACM.

Barsky, L., Baumann, J., Torres, M., \& Aguirre, B. (2007). Managing volunteers: FEMA’s Urban Search and Rescue programme and interactions with unaffiliated responders in disaster response. Disasters, 31(4), 495-507.

Baxter, G., \& Sommerville, I. (2011). Socio-technical systems: From design methods to systems engineering. Interacting with Computers, 23(1), 4-17.

Besselaar, P. van den. (1998). Democratizing Technological Change: Limits to Steering, in Henderson Chatfield, R., Kuhn, S. \& Muller, M. (Eds.). In Proceedings of the Participatory Design Conference, CPSR, Pao Alto, CA, pp. 1-10.

Boehm, B. W., \& Papaccio, P. N. (1988). Understanding and Controlling Software Costs. IEEE Trans. Softw. Eng., 14(10), 1462-1477. 
Bryson, J., Crosby, B., \& Stone, M. (2006). The Design and Implementation of Cross-Sector Collaborations: Propositions from the Literature. Public Administration Review, 66, 44-55.

Burt, E., \& Taylor, J. (2004). Drawing Voluntary Organisations into the Information Polity: Information Resources and Macro Politics. Public Policy and Administration, 19(1), 66-81.

Cavaye, A. L. M. (1995). User participation in system development revisited. Information \& Management, 28(5), 311-323.

Chen, R., Sharman, R., Rao, H. R., \& Upadhyaya, S. (2007). Design principles for critical incident response systems. Information Systems and E-Business Management, 5(3), 201-227.

Christel, M., \& Kang, K. (1992). Issues in Requirements Elicitation (CMU/SEI No. CMU/SEI-92-TR-012).

Christensen, T., Lægreid, P., Roness, P. G., \& Røvik, K. A. (2007). Organization Theory and the Public Sector: Instrument, Culture and Myth. Routledge.

Christensen, T., Laegreid, P., \& Rykkja, L. (2013). Wicked Problems and the Challenge of Transboundary coordination: the case of emergency preparedness and crisis management in Norway. Presented at the COCOPS Working Paper No. 11.

Coakes, E. (2002). Knowledge Management: A Sociotechnical Perspective. In In Knowledge Management in the Sociotechnical World. E. Cokes, D. Willis, S. Clar ke, editors. London: Springer-Verlag. ISBN-13: 9781852334413. p. 4-14.

Creswell, J. W. (2013). Qualitative inquiry and research design: choosing among five approaches. Los Angeles: SAGE Publications.

Davis, M. C., Challenger, R., Jayewardene, D. N. W., \& Clegg, C. W. (2014). Advancing socio-technical systems thinking: A call for bravery. Applied Ergonomics, 45(2, Part A), 171-180.

Denzin, N. K., \& Lincoln, Y. S. (Eds.). (2011). The SAGE Handbook of Qualitative Research (Fourth Edition edition.). Thousand Oaks: SAGE Publications, Inc.

Ehn, P. (1993). Scandinavian Design: on Participation and Skill. In Schuler, D. \& Namioka, A. (Eds.)

Participatory Design. Principles and Practices , Lawrence Earlbaum , Hillsdale, NJ, pp. 41-77.

Ehn, P., \& Kyng, M. (1987). The Collective Resource Approach to Systems Design. In in Ehn, P., Kyng, M. \& Bjerknes, G. (Eds.) Computers and Democracy , Avebury, Aldershot, UK, pp. 19-57.

Emery, F. E., \& Trist, E. L. (1960). Socio-technical systems. In Systems thinking (F.E. Emery., pp. 83-97). Harmondsworth: Penguin.

Fischer, P., Krueger, J. I., Greitemeyer, T., Vogrincic, C., Kastenmüller, A., Frey, D., Heene, M., Wicher, M., \& Kainbacher, M. (2011). The bystander-effect: A meta-analytic review on bystander intervention in dangerous and non-dangerous emergencies. Psychological Bulletin, 137(4), 517-537.

Fleishman, R. (2009). To Participate or Not to Participate? Incentives and Obstacles for Collaboration. In In The Collaborative Public Manager: New Ideas for the Twenty-First Century, edited by R. O’Leary and L. Bingham. Washington, D.C. Georgetown University Press.

Gazley, B. (2008). Inter-Sectoral Collaboration and the Motivation to Collaborate: Toward an Integrated Theory. In in Bingham, L.B. and O’Leary, R. (eds) Big Ideas in Collaborative Public Management New York: M.E.Sharpe.

Goldsmith, S., \& Eggers, W. D. (2004). Governing by Network: The New Shape of the Public Sector. Washington, D.C: Brookings Institution Press and the Innovations in American Government Program at the John F. Kennedy School of Government at Harvard University. 
Graham, M., Phillips, C., Lyons, D., \& Clement, A. (1998). Building a Room of Our Own: The Cooperative Design of Web-based Group Project Support for an Educational Comminity. PDC, 219-228.

Grant, A. M., Fried, Y., \& Juillerat, T. (2011). Work matters: Job design in classic and contemporary perspectives. In APA handbook of industrial and organizational psychology, Vol 1: Building and developing the organization (pp. 417-453). Washington, DC, US: American Psychological Association.

Greenbaum, J., \& Kyng, M. (1991). Design at Work: Cooperative Design of Computer Systems.

Grudinschi, D., Kaljunen, L., Hokkanen, T., Hallikas, J., Sintonen, S., Puustinen, A., Grudinschi, D., Kaljunen, L., ... Puustinen, A. (2013). Management Challenges in Cross-Sector Collaboration: Elderly Care Case Study. The Innovation Journal, 18(2).

Gunnarsson, B., \& Svavarsdóttir, H. (2007). Ambulance Transport and Services in the Rural Areas of Iceland, Scotland and Sweden. Journal of Emergency Primary Health Care, 5, 1-12.

Haddow, G., Bullock, J., \& Coppola, D. P. (2013). Introduction to Emergency Management, Fifth Edition (5 edition.). Waltham, MA: Butterworth-Heinemann.

Hallstrom, A., Ornato, J., Weisfeldt, M., Travers, A., Christenson, J., McBurnie, M., Zalenski, R., Becker, L., ... Proschan, M. (2004). Public-Access Defibrillation and Survival after Out-of-Hospital Cardiac Arrest. New England Journal of Medicine, 351(7), 637-646.

Iivari, J., Isomäki, H., \& Pekkola, S. (2010). The user - the great unknown of systems development: reasons, forms, challenges, experiences and intellectual contributions of user involvement. Information Systems Journal, 20(2), 109-117.

Jack, G. (2005). Equipping First Responders. Compliance Magazine. Retrieved from http://www.highbeam.com/doc/1P3-842896491.html

Jungk, R., \& Müllert, N. R. (1987). Future Workshops: How to Create Desirable Futures. Institute for Social Inventions.

Karat, J. (1996). User Centered Design: Quality or Quackery? Interactions, 3(4), 18-20.

Karlsson, F., Holgersson, J., Söderström, E., \& Hedström, K. (2012). Exploring user participation approaches in public e-service development. Government Information Quarterly, 29(2), 158-168.

Kensing, F., \& Blomberg, J. (1998). Participatory Design: Issues and Concerns. Computer Supported Cooperative Work (CSCW), 7(3-4), 167-185.

Kettl, D. F. (2005). The Global Public Management Revolution (second edition.). Washington, D.C: Brookings Institution Press.

Ki Kim, J., \& Sharman, R. (2006). Framework for Analyzing Critical Incident Management Systems (CIMS)., 4.

Kyng, M. (2010). Bridging the Gap Between Politics and Techniques: On the next practices of participatory design. Scandinavian Journal of Information Systems, 22(1). Retrieved from http://aisel.aisnet.org/sjis/vol22/iss1/5

Larson, R. C., Metzger, M. D., \& Cahn, M. F. (2006). Responding to Emergencies: Lessons Learned and the Need for Analysis. Interfaces, 36(6), 486-501.

Laudon, K. C., \& Laudon, J. P. (1999). Management Information Systems: Organization and Technology in the Networked Enterprise (6 Sub edition.). Upper Saddle River, NJ: Prentice Hall.

Lee, H. J., \& Winters, C. A. (2012). Testing Rural Nursing Theory: Perceptions and Needs of Service Providers. Online Journal of Rural Nursing and Health Care, 4(1), 51-63. 
Leveson, N. (2012). Engineering a Safer World: Systems Thinking Applied to Safety (1st edition.). Cambridge, Mass: The MIT Press.

Levine, S., \& White, P. E. (1961). Exchange as a Conceptual Framework for the Study of Interorganizational Relationships. Administrative Science Quarterly, 5(4), 583-601.

Lindell, M. K., Tierney, K. J., \& Perry, R. W. (2001). Facing the Unexpected:: Disaster Preparedness and Response in the United States. Joseph Henry Press.

Mumford, E. (2000). Socio-Technical Design: An Unfulfilled Promise or a Future Opportunity? In R.

Baskerville, J. Stage, \& J. I. DeGross (Eds.), Organizational and Social Perspectives on Information Technology (pp. 33-46). Springer US.

Mumford, E. (2006). The story of socio-technical design: reflections on its successes, failures and potential. Information Systems Journal, 16(4), 317-342.

Myers, M. D. (2009). Qualitative Research in Business \& Management. Los Angeles: SAGE Publications Ltd.

Nævestad, T.-O. (2009). Mapping Research on Culture and Safety in High-Risk Organizations: Arguments for a Sociotechnical Understanding of Safety Culture (SSRN Scholarly Paper No. ID 1410333). Rochester, NY:

Social Science Research Network.

Norman, D. A., \& Draper, S. W. (1986). User Centered System Design; New Perspectives on Human-Computer Interaction. Hillsdale, NJ, USA: L. Erlbaum Associates Inc.

Ödlund, A. (2010). Pulling the Same Way? A Multi-Perspectivist Study of Crisis Cooperation in Government. Journal of Contingencies and Crisis Management, 18(2), 96-107.

O’Leary, R., \& Bingham, L. B. (2009). The Collaborative Public Manager: New Ideas for the Twenty-first Century. Georgetown University Press.

Oostveen, A.-M., \& van den Besselaar, P. (2004). From Small Scale to Large Scale User Participation: A Case Study of Participatory Design in e-Government Systems. In Proceedings of the Eighth Conference on Participatory Design: Artful Integration: Interweaving Media, Materials and Practices - Volume 1 (pp. 173-182). New York, NY, USA: ACM.

Orlikowski, W. J., \& Iacono, C. S. (2001). Research Commentary: Desperately Seeking the “IT” in IT ResearchA Call to Theorizing the IT Artifact. Info. Sys. Research, 12(2), 121-134.

Palm, J., \& Törnqvist, E. (2008). Governing the sea rescue service in Sweden: communicating in networks [Elektronisk resurs]. Journal of Risk Research, 11:1, s. 269-280.

Pilemalm, S., Hallberg, N., Sparf, M., \& Niclason, T. (2012). Practical experiences of model-based development: Case studies from the Swedish Armed Forces. Systems Engineering, 15(4), 407-421.

Pilemalm, S., Lindgren, I., \& Ramsell, E. (2015). Fourth Generation of User-centered Design - Developing for E-government and Cross-sector Collaborations. In Electronic Government and Electronic Participation (Vol. 22, pp. 178 - 192).

Pilemalm, S., Stenberg, R., \& Granberg, T. A. (2013). Emergency Response in Rural Areas: International Journal of Information Systems for Crisis Response and Management, 5(2), 19-31.

Pilemalm, S., \& Timpka, T. (2008). Third generation participatory design in health informatics-Making user participation applicable to large-scale information system projects. Journal of Biomedical Informatics, 41(2), 327-339.

Quarantelli, E. L. (1994). Emergent Behaviors and Groups in the Crisis Time Periods of Disaster. Retrieved from http://udspace.udel.edu/handle/19716/591 
Quarantelli, E. L. (2000). Emergencies, Disasters and Catastrophes Are Different Phenomena. Retrieved from http://udspace.udel.edu/handle/19716/674

Rasmussen, J., \& Svedung, I. (1997). Proactive Risk Management in a Dynamic Society. Statens räddningsverk.

Reddy, M., Pratt, W., Dourish, P., \& Shabot, M. M. (2003). Sociotechnical requirements analysis for clinical systems. Methods of Information in Medicine, 42(4), 437-444.

Robinson, D., \& Reed, V. (Eds.). (1998). The A-Z of Social Research Jargon. Aldershot, Hants, England ; Brookfield, Vt., USA: Ashgate Publishing Limited.

Schraagen, J. M., \& Ven, J. van de. (2011). Human factors aspects of ICT for crisis management. Cognition, Technology \& Work, 13(3), 175-187.

Schuler, D., \& Namioka, A. (Eds.). (1993). Participatory Design: Principles and Practices. Hillsdale, NJ, USA: L. Erlbaum Associates Inc.

Seidman, I. (1998). Interviewing as Qualitative Research: A Guide for Researchers in Education and the Social Sciences. Teachers College Press.

Sommerville, I. (2004). Software Engineering, 7th Edition (7 edition.). Boston: Addison Wesley.

Stake, R. E. (2000). The SAGE Handbook of Qualitative Research. (N. K. Denzin \& Y. S. Lincoln, Eds.) (Second Edition edition.). Thousand Oaks: SAGE Publications, Inc.

Stenberg, R., Blondin, M., \& Andersson Granberg, T. (2010). Förstainsatsaktörer - Vad är det egentligen? Pilotprojekt för forskning om förstainsatsaktörer (FIA) - forskningsperspektiv och praktiker (CARER rapport, nr 1). Linköping University Electronic Press.

Sund, B. (2006). Sambruk av samhällets jour- och beredskapsresurser är lönsamt![ Is cooperative use of the on call and emergency standby resources profitable?]. Räddningsverket[Rescue Services Agency]: Karlstad.

Swanson, E. B. (1974). Management Information Systems: Appreciation and Involvement. Management Science, 21(2), 178-188.

Thomson, A. M., \& Perry, J. L. (2006). Collaboration Processes: Inside the Black Box. Public Administration Review, 66, 20-32.

Tierney, K., Bevc, C., \& Kuligowski, E. (2006). Metaphors Matter: Disaster Myths, Media Frames, and Their Consequences in Hurricane Katrina. The ANNALS of the American Academy of Political and Social Science, 604(1), 57-81.

Turoff, M., Chumer, M., Walle, B., \& Yao, X. (2004). The Design of a Dynamic Emergency Response Management Information System (DERMIS). Journal of Information Technology Theory and Application (JITTA), 5(4). Retrieved from http://aisel.aisnet.org/jitta/vol5/iss4/3

Valenzuela, T. D., Roe, D. J., Nichol, G., Clark, L. L., Spaite, D. W., \& Hardman, R. G. (2000). Outcomes of Rapid Defibrillation by Security Officers after Cardiac Arrest in Casinos. New England Journal of Medicine, 343(17), 1206-1209.

Venema, A. M., Groothoff, J. W., \& Bierens, J. J. L. M. (2010). The role of bystanders during rescue and resuscitation of drowning victims. Resuscitation, 81(4), 434-439.

Vigoda, E. (2003). Managing Collaboration in Public Administration: The Promise of Alliance among Governance, Citizens, and Businesses. Westport, Conn: Praeger.

Walker, G. H., Jenkins, D. P., Rafferty, L. A., Lenné, M. G., Stanton, N. A., \& Salmon, P. M. (2012). Human Factors Methods and Accident Analysis: Practical Guidance and Case Study Applications. Ashgate Publishing, Ltd. 
Walker, G. H., Stanton, N. A., Salmon, P. M., \& Jenkins, D. P. (2008). A review of sociotechnical systems theory: a classic concept for new command and control paradigms. Theoretical Issues in Ergonomics Science, 9(6), 479-499.

Walle, B., \& Turoff, M. (2006). ISCRAM: growing a global R\&amp;D community on information systems for crisis response and management. International Journal of Emergency Management, 3(4), 364.

Walle, B., \& Turoff, M. (2008). Decision support for emergency situations. Information Systems and E-Business Management, 6(3), 295-316.

Waugh, W. L., \& Streib, G. (2006). Collaboration and Leadership for Effective Emergency Management. Public Administration Review, 66, 131-140.

Weinholt, Å., \& Andersson Granberg, T. (2013). Evaluation of Enhanced Collaboration Between Fire and Rescue Services and Security Officers. Presented at the Proceedings of the 2013 Information Systems for Crisis Response and Management (ISCRAM) conference, Baden Baden, GE.

Weisfeldt, M. L., Sitlani, C. M., Ornato, J. P., Rea, T., Aufderheide, T. P., Davis, D., Dreyer, J., Hess, E. P., ... ROC Investigators. (2010). Survival after application of automatic external defibrillators before arrival of the emergency medical system: evaluation in the resuscitation outcomes consortium population of 21 million. Journal of the American College of Cardiology, 55(16), 1713-1720.

Woltjer, R., Lindgren, I., \& Smith, K. (2006). A case study of information and communication technology in emergency management training. International Journal of Emergency Management, 3(4), 332.

Yin, R. K. (2012). Applications of Case Study Research. SAGE.

Yin, R. K. (2013). Case Study Research: Design and Methods. SAGE Publications.

Young, R. R. (2002). Recommended Requirements Gathering Practices, in CrossTalk. The Journal of Defense Software Engineering. Retrieved from http://www.crosstalkonline.org/storage/issuearchives/2002/200204/200204-Young.pdf

Yousefi Mojir, K., \& Pilemalm, S. (2013). A Framework for “New Actors” in Emergency Response Systems. In Proceedings of the 10th International ISCRAM Conference - Baden-Baden, Germany.

Yousefi Mojir, K., \& Pilemalm, S. (2014). Emerging communities of collaboration: co-location in emergency response systems in Sweden. In Proceedings of the 11th International ISCRAM Conference, Penn State, USA. 


\section{Figures, Images and Tables}

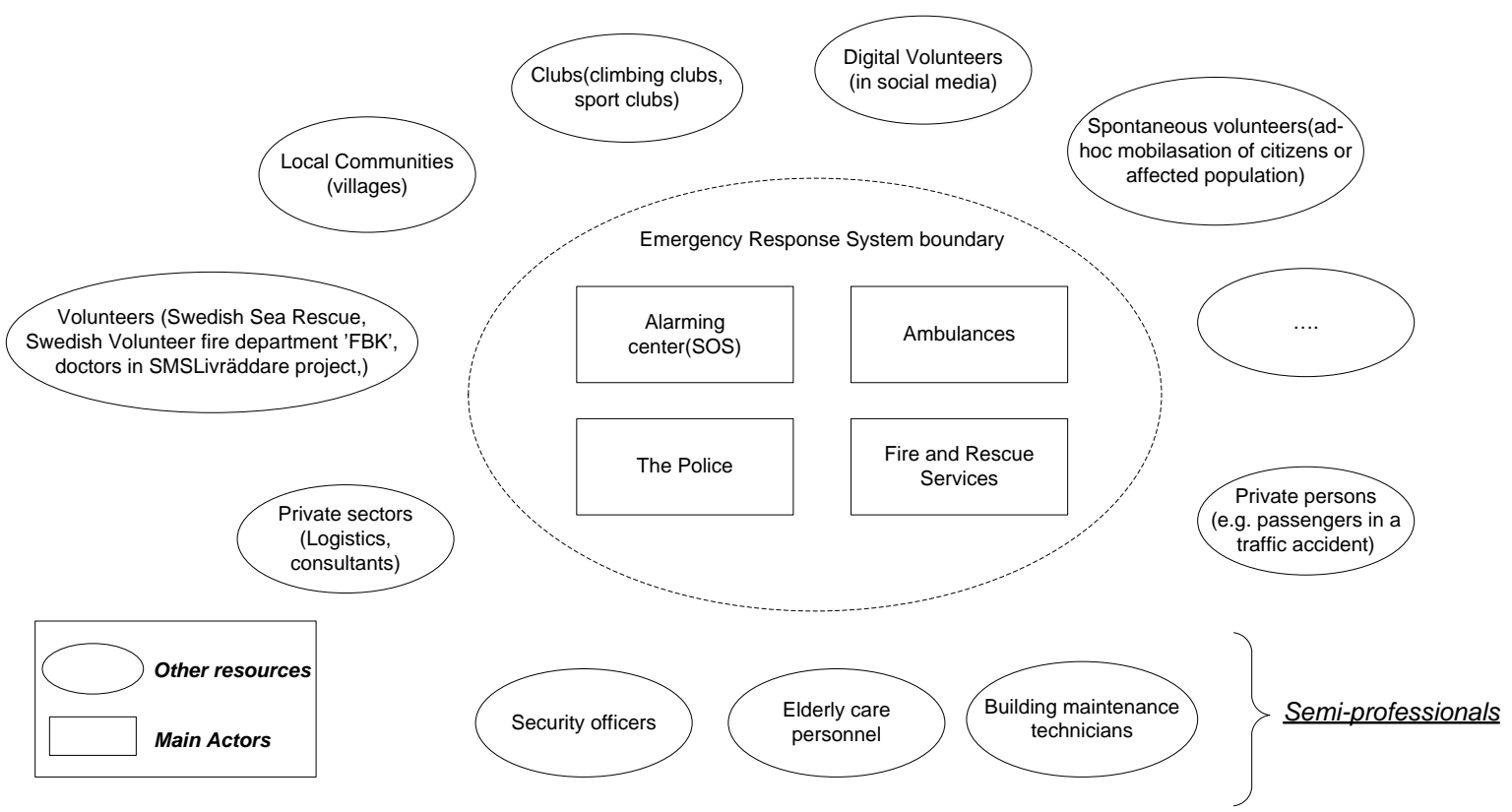

Figure 1. The system boundary of emergency management in Sweden (simplified illustration).

Table1: Summary of data collection. The first column shows the methods used in data collection. The next column shows the data source and organisation level. The "Reference" column indicates the name used to refer to the data source in the remainder of the text. The last column contains detailed information about the participants.

\begin{tabular}{|c|c|c|c|c|c|}
\hline Method & Source & $\begin{array}{l}\text { Organisational } \\
\text { Level }\end{array}$ & $\begin{array}{l}\text { Reference } \\
\text { in this } \\
\text { paper }\end{array}$ & Participant(s) & Examples \\
\hline \multirow{8}{*}{ Interviews } & \multirow{3}{*}{ MSB } & \multirow{3}{*}{ Strategic } & Interview 1 & $\begin{array}{l}\text { Works at the MSB with } \\
\text { strengthening the response capacity } \\
\text { in the Swedish ERS at strategic level }\end{array}$ & $\begin{array}{l}\text { Involving new actors such as } \\
\text { semi-professionals to help the fire } \\
\text { and rescue services }\end{array}$ \\
\hline & & & Interview 2 & $\begin{array}{l}\text { Works at the MSB on costs/benefits } \\
\text { analysis of the cooperative use of } \\
\text { resources in the Swedish ERS }\end{array}$ & $\begin{array}{l}\text { To shorten response time in the } \\
\text { case of heart attacks with the help } \\
\text { of new resources }\end{array}$ \\
\hline & & & Interview 3 & $\begin{array}{l}\text { Works at the MSB with using } \\
\text { volunteers actors in the Swedish } \\
\text { ERS }\end{array}$ & $\begin{array}{l}\text { Involving volunteers such as car } \\
\text { and climbing clubs }\end{array}$ \\
\hline & $\begin{array}{l}\text { Södertälje } \\
\text { Municipality }\end{array}$ & Operative & $\begin{array}{l}\text { Interview } 4 \\
\text { (Focus } \\
\text { group) }\end{array}$ & $\begin{array}{l}\text { Three security guards in Södertälje } \\
\text { municipality in Sweden }\end{array}$ & $\begin{array}{l}\text { Collaboration between the fire } \\
\text { and rescue services and security } \\
\text { guards }\end{array}$ \\
\hline & \multirow{6}{*}{ Safety House } & Administrative & Interview 5 & Project manager & $\begin{array}{l}\text { Co-location of main and } \\
\text { supportive actors at the Safety } \\
\text { House }\end{array}$ \\
\hline & & \multirow{3}{*}{ Operative } & Interview6 & Police representative & $\begin{array}{l}\text { The police involvement in the co- } \\
\text { location }\end{array}$ \\
\hline & & & Interview 7 & $\begin{array}{l}\text { Fire and rescue services } \\
\text { representative }\end{array}$ & $\begin{array}{l}\text { The rescue services involvement } \\
\text { in the co-location }\end{array}$ \\
\hline & & & Interview 8 & Swedish Defence representative & $\begin{array}{l}\text { The Swedish Defence involvement } \\
\text { in the co-location }\end{array}$ \\
\hline $\begin{array}{l}\text { Future } \\
\text { workshop }\end{array}$ & & $\begin{array}{l}\text { Operative+ } \\
\text { Administrative }\end{array}$ & $\begin{array}{l}\text { Future } \\
\text { workshop }\end{array}$ & $\begin{array}{l}\text { Representatives from the police, the } \\
\text { fire and rescue services, Swedish } \\
\text { Defence, the Municipality of } \\
\text { Östersund, and the project manager }\end{array}$ & $\begin{array}{l}\text { Analysis of needs of ISs to } \\
\text { improve the co-location }\end{array}$ \\
\hline $\begin{array}{l}\text { Participant } \\
\text { observation }\end{array}$ & & Operative & $\begin{array}{l}\text { Participant } \\
\text { observation }\end{array}$ & $\begin{array}{l}\text { Representatives from the police, } \\
\text { fire and rescue services, and the } \\
\text { alarm centres }\end{array}$ & $\begin{array}{l}\text { Observation of the physical } \\
\text { setting at the Safety House }\end{array}$ \\
\hline
\end{tabular}




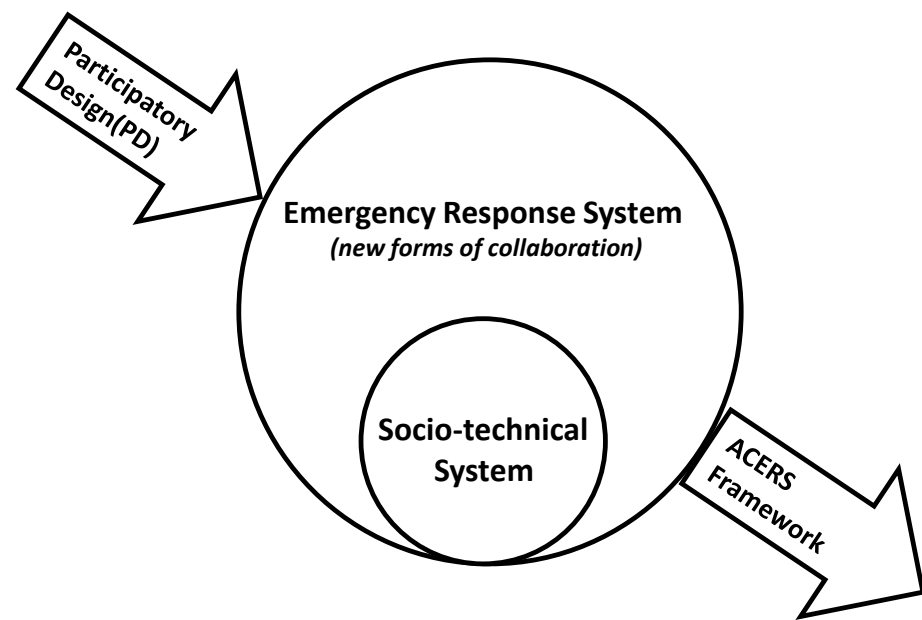

Figure 2: Combining participatory design, socio-technical system theory and the ERS context in the ACERS framework

\section{Actor-Centered Emergency Response System (ACERS)}

B) Task/ Response operation

B1) Task and Responsibility

B2) Availability/ Accessibility

B3) Incident Type

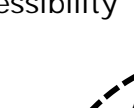

A)

\section{C) Technology}

C1) Communication Method

C2) Information Technology

C3) Emergency supplies

\section{A) Actors}

A1) Type/Role

A2) Attitude

A3) Training

A4) Background

\section{A4) Background}

D1) Organisational Structure

E1) Environment

D2) Leadership

D3) Costs/Benefits

E2) Regulation and Legal Issues

D) Structure/ Organization

E) Environment/ Context

Figure 3: The ACERS framework, showing parent dimension and sub-dimensions 